\title{
Culture-induced changes in mRNA expression levels of efflux and SLC-transporters in brain endothelial cells
}

\author{
C. Goldeman, B. Ozgür and B. Brodin*
}

\begin{abstract}
Background: The complexity of the neurovascular unit (NVU) poses a challenge in the investigations of drug transport across the blood-brain barrier (BBB) and the function of the brain capillary endothelium. Several in vitro models of the brain capillary endothelium have been developed. In vitro culture of primary endothelial cells has, however, been reported to alter the expression levels of various brain endothelial proteins. Only a limited number of studies have addressed this in detail. The aim of the present study was to investigate mRNA levels of selected BBB transporters and markers in in vitro models of the BBB based on bovine primary endothelial cells and compare these to the levels estimated in freshly isolated bovine brain capillaries.
\end{abstract}

Methods: Brain capillaries were isolated from bovine cerebral cortex grey matter. Capillaries were seeded in culture flasks and endothelial cells were obtained using a brief trypsinization. They were seeded onto permeable supports and cultured in mono-, non-contact- or contact co-culture with/without primary rat astrocytes. mRNA-expression levels of the selected BBB markers and transporters were evaluated using $\mathrm{QPCR}$ and monolayer integrity of resulting monolayers was evaluated by measuring the transendothelial electrical resistance (TEER).

Results: The capillary mRNA transcript profile indicated low expression of $A B C C 1$ and $C L D N 1$. The mRNA expression levels of TPA, OCLN, ABCB1, SLC2A1, SLC16A1 and SLC7A5 were significantly decreased in all culture configurations compared to freshly isolated bovine brain capillaries. $A L P, V W F, A B C C 1$ and $A B C C 4$ were upregulated during culture, while the mRNA expression levels of F11R, TJP1, CLDN5, CLDN1 and ABCG2 were found to be unaltered. The mRNA expression levels of $W W F, A L P, A B C B 1$ and $A B C C 1$ were affected by the presence of rat astrocytes.

Conclusion: The endothelial mRNA transcript profile in bovine capillaries obtained in this study correlated nicely with profiles reported in mice and humans. Cultured endothelial cells drastically downregulated the mRNA expression of the investigated SLC transporters but maintained expression of efflux transporter and junctional protein mRNA, implying that the bovine in vitro BBB models may serve well to investigate basic barrier biology and in vivo permeation of passively permeating compounds and efflux transporter substrates but may be less well suited for investigations of SLC-mediated transport.

Keywords: Blood-brain barrier, Brain endothelium, qPCR, In vitro culture, Co-culture, SLC transporters

*Correspondence: Birger.brodin@sund.ku.dk Department of Pharmacy, Faculty of Health and Medical Sciences, University of Copenhagen, Universitetsparken 2, 2100 Copenhagen, Denmark

\begin{abstract}
Introduction
The endothelium of the small brain capillaries makes up the blood-brain barrier (BBB). Together with pericytes and astrocytic end-feets, they serve as a restrictive barrier for passage of a wide range of structurally diverse compounds, including most drug compounds. This
\end{abstract}


function is due to the presence of tight junctions (TJs) between the adjacent endothelial cells, efflux transporters and metabolizing enzymes (for references, see [1]). The trans-endothelial transport of nutrients and micronutrients occurs via uptake transporters (solute carriers) and receptors, that are highly regulated.

Several in vitro models of the BBB with brain capillary endothelial cells grown on permeable supports have been developed. These models are widely used to investigate drug transport mechanisms across the $\mathrm{BBB}$, predict CNS drug exposure and to investigate interactions between the cell types of the neurovascular unit (NVU) [6, 18, 21]. Attempts of developing in vitro models of the BBB have included the use of immortalized cell lines from animal or human origin, primary endothelial cells isolated from animal sources (e.g. murine, bovine or porcine) and recently, human induced pluripotent stem cells that have been differentiated towards a brain endothelial phenotype [17, 22, 23, 35]. In general, immortalized cell lines tend to express a wide range of endothelial marker proteins, but they do, however, exhibit low expression of $\mathrm{TJ}$ proteins, resulting in cell culture models with low barrier integrity [15]. In vitro BBB models based on isolated primary cells retain many important properties of the $\mathrm{BBB}$ by expressing BBB-specific marker proteins, $\mathrm{TJ}$ proteins, receptor systems and efflux transporters upon cultivation on permeable supports. There are, however, reports of suboptimal expression of transport proteins, especially of the solute carrier (SLC) family, as recently reviewed by Helms et al. [15]. In the present study, we investigated mRNA levels of selected marker proteins from cultured bovine capillary endothelial cells, and compared those to the mRNA levels in freshly isolated brain capillaries in order to probe the effect of in vitro culture. We furthermore investigated whether important $\mathrm{BBB}$ marker genes, efflux pumps/ABC transporters and transport proteins of the SLC family were differentially expressed in brain capillary endothelial cells cultured as monocultures (MC), non-contact co-culture (NCC) and contact co-culture (CCC) with isolated primary rat astrocytes.

We observed that expression levels of efflux transporters were affected by in vitro culture. $A B C B 1$ was downregulated in all culture configurations, whereas $A B C C 1$ and $A B C C 4$ showed elevated expression levels compared to bovine capillaries. The expression level of $A B C G 2$ was not altered. Furthermore, we observed a significant decrease in expression levels of SLC transporters, as SLC2A1, SLC7A5 and SLC16A1 were significantly downregulated in all culture configurations compared to bovine capillaries. TJ protein expression levels were not markedly affected, except for OCLN which was significantly downregulated in $\mathrm{MC}$ and $\mathrm{NCC}$, compared to capillaries.

\section{Materials and methods}

All materials were obtained from Sigma-Aldrich unless otherwise stated.

\section{Isolation of primary bovine capillaries and rat astrocytes}

Bovine brain tissue was obtained from a local abattoir (Mogens Nielsen kreaturslagteri A/S, Herlufmagle, Denmark). The isolation of bovine brain capillaries was performed using a previously described method [16]. Briefly, the leptomeninges were removed and the grey matter was collected in Dulbecco's Modified Eagle's Medium (DMEM) and homogenized. The homogenate was filtered through a $160 \mu \mathrm{m}$ nylon net filter to collect capillary fragments. The collected capillary fragments were centrifuged for $5 \mathrm{~min}$ at $500 \times g$ and the pellet was resuspended in DMEM supplemented with $10 \%$ fetal bovine serum (FBS), $10 \mathrm{ml} / \mathrm{L}$ MEM non-essential amino acids (NEAA) $(\times 100), 100 \mathrm{U} / \mathrm{mL}-100 \mu \mathrm{g} / \mathrm{mL}$ pencillin-streptomycin, $125 \mu \mathrm{g} / \mathrm{mL}$ heparin (DMEM-Comp) and the centrifugation was repeated. Pellets were resuspended in digestive enzyme mix containing $2000 \mathrm{U} / \mathrm{mL}$ Collagenase III, $3400 \mathrm{U} / \mathrm{mL}$ DNAse I and $900 \mathrm{U} / \mathrm{mL}$ Trypsin TRL in DMEM-Comp for $1 \mathrm{~h}$ at $37^{\circ} \mathrm{C}$ in a water bath followed by filtration through a $200 \mu \mathrm{m}$ nylon net filter. After centrifugation for $5 \mathrm{~min}$ at $500 \times g$, the pellets were resuspended in cryo-preservation media consisting of 1:9 DMSO: FBS and cryopreserved for later use. To isolate whole capillaries for the analysis of capillary mRNA expression levels, capillaries were collected before the addition of digestive enzymes. The capillaries were spun down in $16 \%$ dextran $\left(M_{\mathrm{r}}: 450,000-650,000\right)$ in DMEM at $2630 \times g$ for $15 \mathrm{~min}$, followed by an additional $10 \mathrm{~min}$ spin at $485 \times g$.

Primary rat astrocytes were isolated from 6 days old Sprague-Dawley rat pups, as previously described [20]. Pups were euthanized, and the cerebral cortex removed, followed by a gentle homogenization where the tissue was pressed through $80 \mu \mathrm{m}$ nylon mesh into astrocyte media DMEM-I $+20 \%$ serum, consisting of DMEM-AQ, $1 \%$ (v/v) MEM NEAA ( $\times 100), 100 \mathrm{U} / \mathrm{mL}: 100 \mu \mathrm{g} / \mathrm{ml}$ penicillin: streptomycin solution, $2.0 \mathrm{mM}$ L-Glutamine (Sigma G7513) and 20\% FBS. The homogenate was then triturated using a steel canula $\left(13 \mathrm{G}+5^{\prime \prime}\right)$. The cell suspension was plated in un-coated T75 culture flasks and cells were cultured for 4 weeks $\left(37^{\circ} \mathrm{C}, 5 \% \mathrm{CO}_{2}\right)$. Media was changed two times a week, where Ast-DMEM I $+20 \%$ serum was used in the first week, Ast-DMEM I $+15 \%$ serum in the second week, and AST-DMEM II $+10 \%$ Serum (consisting of Ast-DMEM I, $0.25 \mathrm{mM}$ dBcAMP and 10\% FBS) in the remaining 2 weeks. The aspirated medium was collected as during the last 2 weeks of culture. This medium, which was named "astrocyte-conditioned medium" (ACM) was later used during culture of bovine brain capillaries. Astrocytes were dissociated using trypsin-EDTA 
and resuspended in 9:1 FBS: DMSO and cryopreserved until use. Isolated astrocytes were characterized by immunostaining for Glial fibrillary acidic protein (GFAP) and Filamentous-actin to ensure expression of GFAP and a star-shaped morphology, respectively (data not shown).

\section{Endothelial cell culture}

Primary bovine endothelial cells were used after one passage in three different culture configurations in mono culture (MC) and in co-culture with rat astrocytes either as non-contact or co-contact as previously described [16, 18]. Briefly, frozen primary bovine brain capillaries were seeded onto T75 flasks coated with collagen type IV and fibronectin, and cultured in DMEM-Comp + ACM (1:1) for 4 days followed by a trypsinization of the resulting endothelial cells. The cells were subsequently seeded on permeable supports at a seeding density of 90,000 cells/ $\mathrm{cm}^{2}$ and cultured in either mono-, non-contact- or contact- co-culture configurations. Co-culture models were prepared by seeding astrocytes on the bottom of the permeable support or directly into the trays at seeding density of 120,000 cells/well, 2 days prior to endothelial cell seeding. Cells were then cultured for 3 days in DMEMComp. mixed with ACM at a ratio of 1:1 (MC) or DMEMComp (NCC and CCC). After 3 days, the medium was changed to differentiation medium containing DMEM supplemented with $312.5 \mu \mathrm{M}$ 8-(4-CPT)-cyclic adenosine monophosphate, $0.5 \mu \mathrm{M}$ dexamethasone, $17.5 \mu \mathrm{M}$ RO-20-1724 and $50 \mathrm{mM} \mathrm{N}$-[tris(hydroxymethyl)methyl]2 -aminoethanesulfonic acid. The cells were cultured for additional 3 days. All trans endothelial electrical resistance (TEER) measurements were performed on the experimental day after 6 days of culture on permeable supports with an Endohm Chamber connected to an Evom $^{2}$ Meter (WPI, Friedberg, Germany) to verify the presence of a barrier and was accepted if a TEER value of $500 \Omega^{*} \mathrm{~cm}^{2}$ or above was obtained.

\section{mRNA isolation and CDNA synthesis}

mRNA from bovine capillaries was obtained by lysing the capillaries in TrizOL, according to the manufacturer's instructions. mRNA from endothelial cells grown on permeable supports was isolated by using the GenElute $^{\mathrm{TM}}$ Universal Total RNA Purification Kit (A4B0208) or Nucleospin ${ }^{\circledR}$ RNA/Protein kit (Macherey-Nagel, Düren, Germany), according to the manufacturer's instructions. If the GenElute ${ }^{\mathrm{TM}}$ kit was used, the DNAse I kit was used prior to cDNA synthesis. mRNA with concentrations between 0.5 and $1.0 \mu \mathrm{g} / \mu \mathrm{L}$ were used for the synthesis of cDNA using the High Capacity cDNA Reverse Transcription kit (4368814, Thermo Fischer Scientific), according to the manufacturer's instructions. The reverse transcription was accomplished by a PTC-200 Thermal Cycler (MJ
Research, Quebec, Canada). The synthesized cDNA was stored at $-20^{\circ} \mathrm{C}$ until further use.

\section{Real-time quantitative polymerase chain reaction (qPCR)}

The qPCR analysis was performed using a Lightcycler ${ }^{\circledR}$ 96 instrument and the FastStart DNA Master SYBR Green I mixture (Roche, Basel, Switzerland) with Riboloc R1 (Thermo Scientific) as RNAse inhibitor. A mixture of cDNA, primers (in a final concentration of $1 \mu \mathrm{M}$ of forward and reverse primers), Water (PCR-grade) and master mix was used. Primer design was performed using SDSC Biology Workbench and NCBI and all primers were obtained from Thermo Fischer Scientific. The primer specifications are listed in Table 1. A total of 45 cycles were performed after a pre-incubation of $600 \mathrm{~s}$ at $95{ }^{\circ} \mathrm{C}$; each cycle contained a period of $95^{\circ} \mathrm{C}$ for $10 \mathrm{~s}$, $55^{\circ} \mathrm{C}$ for $10 \mathrm{~s}$ and $72{ }^{\circ} \mathrm{C}$ for $20 \mathrm{~s}$, followed by a melting curve determination. Primer efficiencies were determined in-house by finding the slope of a ten-fold serial dilution calibration curve. Primer efficiencies were then calculated using the equation $\mathrm{E}=10^{(-1 / \text { Slope })}$ [31]. The selected primers had efficiencies between 1.9 and 2.1 and melting curves displaying a single product. Selected genes included tight junction proteins Occludin $(O C L N)$, Junction adhesion molecule $1(F 11 R)$, Zonula occludens 1 (TJP1), Claudin-1 (CLDN1) and -5 (CLDN5), efflux transporters P-glycoprotein $(A B C B 1)$, Breast cancer resistance protein $(A B C G 2)$, Multidrug resistance protein $1(A B C C 1)$ and $-4(A B C C 4)$, SLC transporters LAT-1 (SLC7A5), GLUT-1 (SLC2A1) and MCT-1 (SLC16A1), as well as the enzyme Alkaline phosphatase $(A L P)$, Tissue plasminogen activator (TPA) and von Willebrand factor $(V W F)$. A set of three reference genes (HPRT-1, GAPDH and $\beta$-actin) was used to normalize the mRNA expression levels of the genes of interest (see Additional file 1: Figs. S1 and S2 for Ct-values).

\section{Data treatment and statistics}

To convert quantification cycle values $(\mathrm{Cq})$ into normalized relative quantities, we used the $2^{-\Delta \Delta \mathrm{Cq}}$ method proposed by Livak \& Schmittgen [24], but corrected for the estimated efficiency (E): $E^{-\Delta C q}[14,28]$. The ratio between the efficiency corrected mRNA expression of the reference genes and the gene of interest were then determined. Statistical tests in this study were performed using GraphPad Prism software (version 7). Data are shown as mean + standard error of the mean (SEM). All experiments were performed in at least three individual passages ( $\mathrm{n}$ denotes number of passages) originating from different animals, and three technical replicates within each passage ( $\mathrm{N}$ denotes the number of technical replicates), unless otherwise stated. Groups were 
Table 1 Overview of the investigated genes of interest as well as the used reference genes, their gene symbol, name and primers

\begin{tabular}{|c|c|c|c|c|}
\hline Gene symbol & Gene name & PCR efficiency & $\begin{array}{l}\text { Product size } \\
\text { (Bp) }\end{array}$ & Primer sequence ( $5^{\prime}$ to $\left.3^{\prime}\right)$ \\
\hline HPRT1 & Hypoxanthine guanine phosphoribosyl transferase 1 & 2.03 & 144 & $\begin{array}{l}\text { F: CGT GGT GAT TAG CGA TGA TG } \\
\text { R: TTC ATC ACA TCT CGA GCC AG }\end{array}$ \\
\hline ACTB & $\beta$-actin & 1.91 & 426 & $\begin{array}{l}\text { F: AGG CTG TGC TGT CCC TGT AT } \\
\text { R: AGG TAG TTT CGT GAA TGC CG }\end{array}$ \\
\hline GAPDH & Glyceraldeyde-3-phosphate dehydrogenase & 1.93 & 102 & $\begin{array}{l}\text { F: CGA CCA CTT TGT CAA GCT CA } \\
\text { R: GGA CCT TAC TCC TTG GAG GC }\end{array}$ \\
\hline VWF & von Willebrand Factor & 1.92 & 126 & $\begin{array}{l}\text { F: TCT CAC GAG ACT GCA ACA CC } \\
\text { R:TGA AGT GCC TGT CGT CAA AG }\end{array}$ \\
\hline ALP & Alkaline phosphatase & 1.98 & 139 & $\begin{array}{l}\text { F: ATC GGT ACC TGTTTT GCC AG } \\
\text { R:TGA TGA CGT TCTTAG CCA CG }\end{array}$ \\
\hline TPA & Tissue plasminogen activator & 1.96 & 103 & $\begin{array}{l}\text { F: TCTTCT CCG TTC TTTTCC GA } \\
\text { R:TGT TGG TGA CGG TCC TGTTA }\end{array}$ \\
\hline CLDN1 & Claudin-1 & 2.06 & 122 & $\begin{array}{l}\text { F: CCG TTG GCA TGA AGT GTA TG } \\
\text { R: CCA TGC TGT GGC AAC TAA AA }\end{array}$ \\
\hline CLDN5 & Claudin-5 & 2.06 & 122 & $\begin{array}{l}\text { F: CAG AAG TAC GAG CTG GGA GC } \\
\text { R:TAC TTC ACC GGG AAG CTG AA }\end{array}$ \\
\hline OCLN & Occludin & 2.05 & 143 & $\begin{array}{l}\text { F: CCG GAA GAT GAA ATT CTC CA } \\
\text { R: GTT CCA TAG CCT CTG TCC CA }\end{array}$ \\
\hline TJP1 & $\begin{array}{l}\text { Zonula occludens } 1 \\
\text { (Zo-1) }\end{array}$ & 2.08 & 148 & $\begin{array}{l}\text { F: CGA CCA GAT CCT CAG GGT AA } \\
\text { R: GGA TTC TAC GAT GCG ACG AT }\end{array}$ \\
\hline F11R & $\begin{array}{l}\text { Junctional adhesion molecule } 1 \\
\text { (JAM-1) }\end{array}$ & 1.94 & 113 & $\begin{array}{l}\text { F: TGC TGA CCT GCT CAG AGA GA } \\
\text { R: GGA AGA GTT GCT GAA GGC AC }\end{array}$ \\
\hline $\mathrm{ABCB} 1$ & $\begin{array}{l}\text { P-glycoprotein } \\
\text { (Pgp) }\end{array}$ & 1.99 & 127 & $\begin{array}{l}\text { F: CGG GAC AGA AAG CTC AGTTC } \\
\text { R:TAA TGG CGC AAA ATA CAC CA }\end{array}$ \\
\hline ABCG2 & $\begin{array}{l}\text { Breast cancer resistance protein } \\
\text { (BCRP) }\end{array}$ & 2.08 & 139 & $\begin{array}{l}\text { F: CCA GGC GTT CAT TCA AAA AT } \\
\text { R: GCT CTG TTC TGG ATT CCT GC }\end{array}$ \\
\hline $\mathrm{ABCC} 1$ & $\begin{array}{l}\text { Multidrug resistance protein } 1 \\
\text { (MRP-1) }\end{array}$ & 2.03 & 106 & $\begin{array}{l}\text { F: GTT CCC CTC AAT GCT GTG AT } \\
\text { R:TCC CGT TGA GAA TTT CGTTC }\end{array}$ \\
\hline ABCC4 & $\begin{array}{l}\text { Multidrug resistance protein } 4 \\
\text { (MRP-4) }\end{array}$ & 1.95 & 124 & $\begin{array}{l}\text { F: ATT AAA CGC CTG GAA TGT GC } \\
\text { R: GTG CAT TGA ACA GCT CCT GA }\end{array}$ \\
\hline SLC2A1 & $\begin{array}{l}\text { Glucose transporter } 1 \\
\text { (GLUT-1) }\end{array}$ & 1.92 & 139 & $\begin{array}{l}\text { F: TAC CCC AAG AGG TGG CTA TG } \\
\text { R: CTG GTC TCA GGC AAG GAA AG }\end{array}$ \\
\hline SLC7A5 & $\begin{array}{l}\text { L-type amino acid transporter } 1 \\
\text { (LAT-1) }\end{array}$ & 1.91 & 111 & $\begin{array}{l}\text { F: TAG CCA ATC TGG ATC CCA AG } \\
\text { R: TCA AGT AAT TCC ATC CCC CA }\end{array}$ \\
\hline SLC16A1 & $\begin{array}{l}\text { Monocarboxylate transporter } 1 \\
\text { (MCT-1) }\end{array}$ & 1.91 & 143 & $\begin{array}{l}\text { F: TTT ACG CCT TTG ATT CCC AG } \\
\text { R:TCC CTA TTG GTT TCT GTG GG }\end{array}$ \\
\hline
\end{tabular}

The primer sequence, $\mathrm{PCR}$ efficiency and product size are listed for each of the designed primer sets

$P C R$ Polymerase chain reaction, $B p$ base pairs, $F$ forward, $R$ reverse

compared using an ANOVA test (one way), followed by a Tukey post test. $\mathrm{P}<0.05$ was considered significant.

For Fig. 5, data on human and murine brain capillary endothelial cells were derived from two transcriptomic databases developed by Betsholtz lab [13, 34] and Barres lab [37, 38], respectively. Data were derived as mean expression levels from the respective database, and the mean expression levels were normalized against the corresponding expression levels of HPRT-1, GAPDH and $\beta$-actin reported in databases. In addition, the quantitative expression levels of tight junctions and efflux transporters found in the fresh bovine brain capillaries and in endothelial cells cultured in co-contact configuration (plotted in Figs. 2 and 3) were replotted as mean values alongside with data from the transcriptomic databases for a rough visual comparison. Data from the databases were derived as mean values. The data reported in Betsholtz' database were generated from two mice (Cldn5-GFP;Cspg4-DsRed genotype) $[13,34]$. The murine and human data derived from Barres' database are from two biological replicates 
of Tie2-EGFP transgenic mice $(n=2)$ and from two patients $(n=2)$, respectively $[37,38]$.

\section{Results}

The present study aimed to elucidate to what extent downregulation of mRNA expression of important $\mathrm{BBB}$ endothelial genes occurred during culture of in vitro $\mathrm{BBB}$ models. Furthermore, it was investigated to what degree co-culture with astrocytes could "rescue" the BBB phenotype in cultured brain capillary endothelial cells, i.e. increase transcript levels which were downregulated in vitro in mono cultures. In vitro mRNA transcript levels were measured in three different culture configurations, monoculture (MC), non-contact co-culture (NCC) and contact co-culture (CCC) (schematic drawing in Fig. 1a) and compared with the mRNA levels in freshly isolated intact brain capillaries.
The brain endothelial markers von Willebrand factor and alkaline phosphatase were highly expressed in cultured endothelial cells

The mRNA expressions level of three typical brain endothelium markers, von Willebrand factor $(V W F)$, Alkaline phosphatase $(A L P)$ and Tissue plasminogen activator $(T P A)$ were investigated. The in vitro cultures of bovine brain capillary endothelial cells in mono culture and co-culture with astrocytes were compared to that estimated in intact brain capillaries. VWF was found to be highly expressed in all in vitro model configurations, and significantly higher mRNA expression levels were observed in endothelial cells co-cultured with astrocytes, as compared to the expression level in intact brain capillaries (Fig. 1b). The mRNA expression level of $V W F$ in MC showed a clear tendency to increase as compared to intact capillaries, but statistically non-significant. Contrary to $V W F$, the mRNA expression levels of $A L P$ did not differ significantly between the different culture conditions and brain capillaries. However, a tendency of mRNA expression

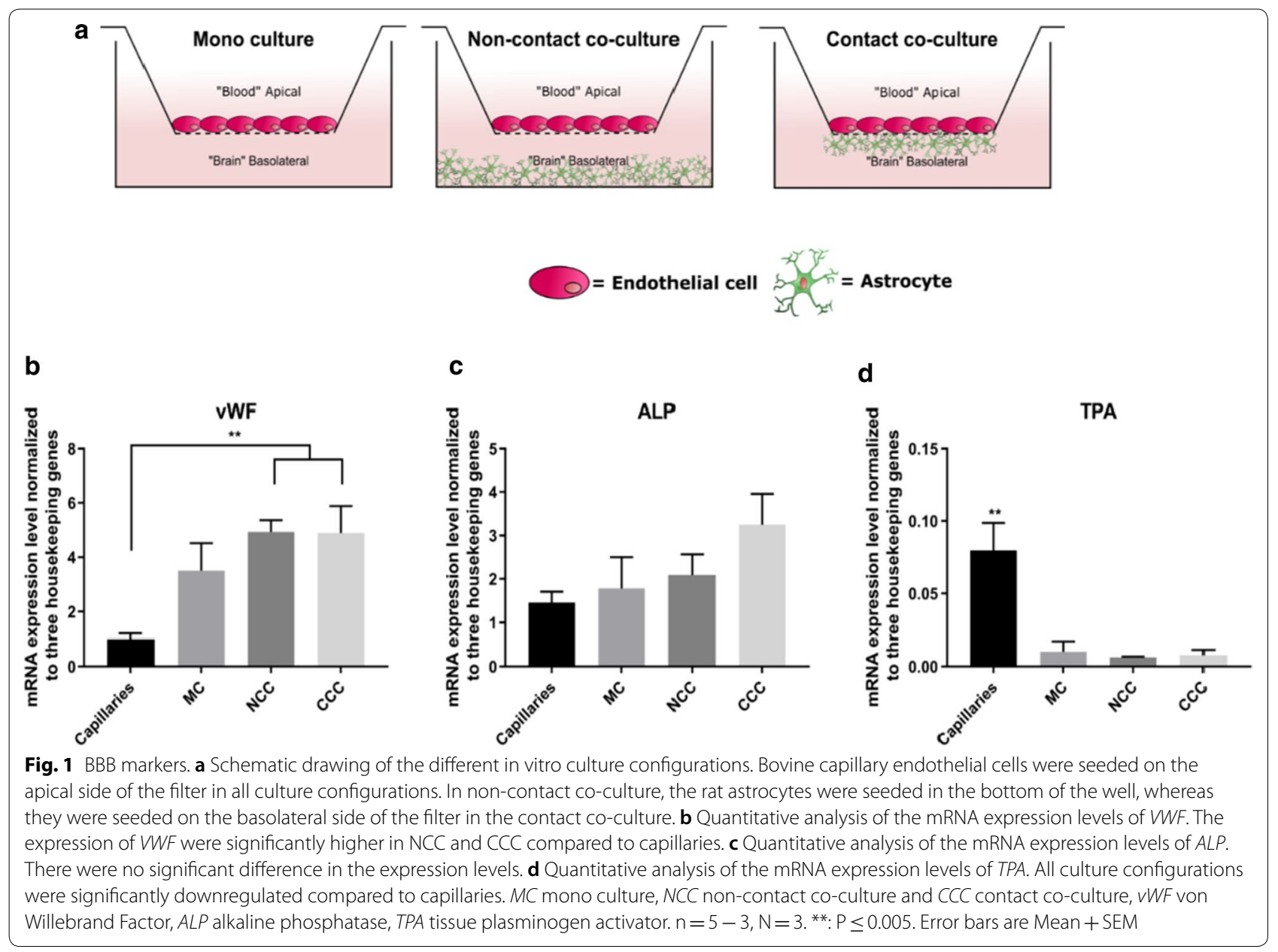


elevation was observed in CCC compared to expression levels estimated in MC, NCC and intact brain capillaries, indicating that the presence of astrocytes influenced induced the mRNA expression levels of $A L P$ (Fig. 1c). For TPA, on the other hand, we observed a significantly lower expression level in all culture configurations as compared to the expression level estimated in bovine brain capillaries (Fig. 1d).

\section{mRNA levels of tight junction-associated proteins}

\section{claudin-5, claudin-1, zo-1 and JAM1 were not changed} by culture, whereas occludin transcript levels decreased

Tight junction proteins (TJs) are highly expressed in the brain capillary endothelial cells resulting in an extremely tight and polarized barrier that selectively controls trafficking of molecules between the blood and CNS. TJs are complex structures that rapidly undergo alterations in expression levels. We measured the transcript levels of the brain endothelial TJ proteins Claudin-1 and -5, Occludin and Zo-1 (CLDN1, CLDN5, $O C L N$ and TJP1) and the junctional adhesion molecule
1, JAM-1, $(F 11 R)$ in brain capillary endothelial cells to see whether TJ complex transcripts were downregulated by in vitro culture, and whether the expression levels could be increased by co-culture with astrocytes. The transcript levels of CLDN5 were similar in capillaries, MC, NCC and CCC (Fig. 2d). TJP1 and F11R transcript levels showed a similar pattern (Fig. 2a, b). These results indicated that transcript levels of these genes were unaffected by in vitro culture or the presence of astrocytes. The expression level of OCLN was found to be significantly downregulated in endothelial cells cultured in MC and NCC, as compared to the level estimated in intact brain capillaries. Expression levels of OCLN in CCC were increased as compared to MC and $\mathrm{NCC}$ and was not significantly different from expression levels in capillaries (Fig. 2c). CLDN1 transcript levels were low in capillaries and in all culture configurations (Fig. 2e) and no significant differences were observed, indicating absence of CLDN1 from capillary endothelial cells, both in vivo and in vitro. The transendothelial electrical resistance (TEER) of the different
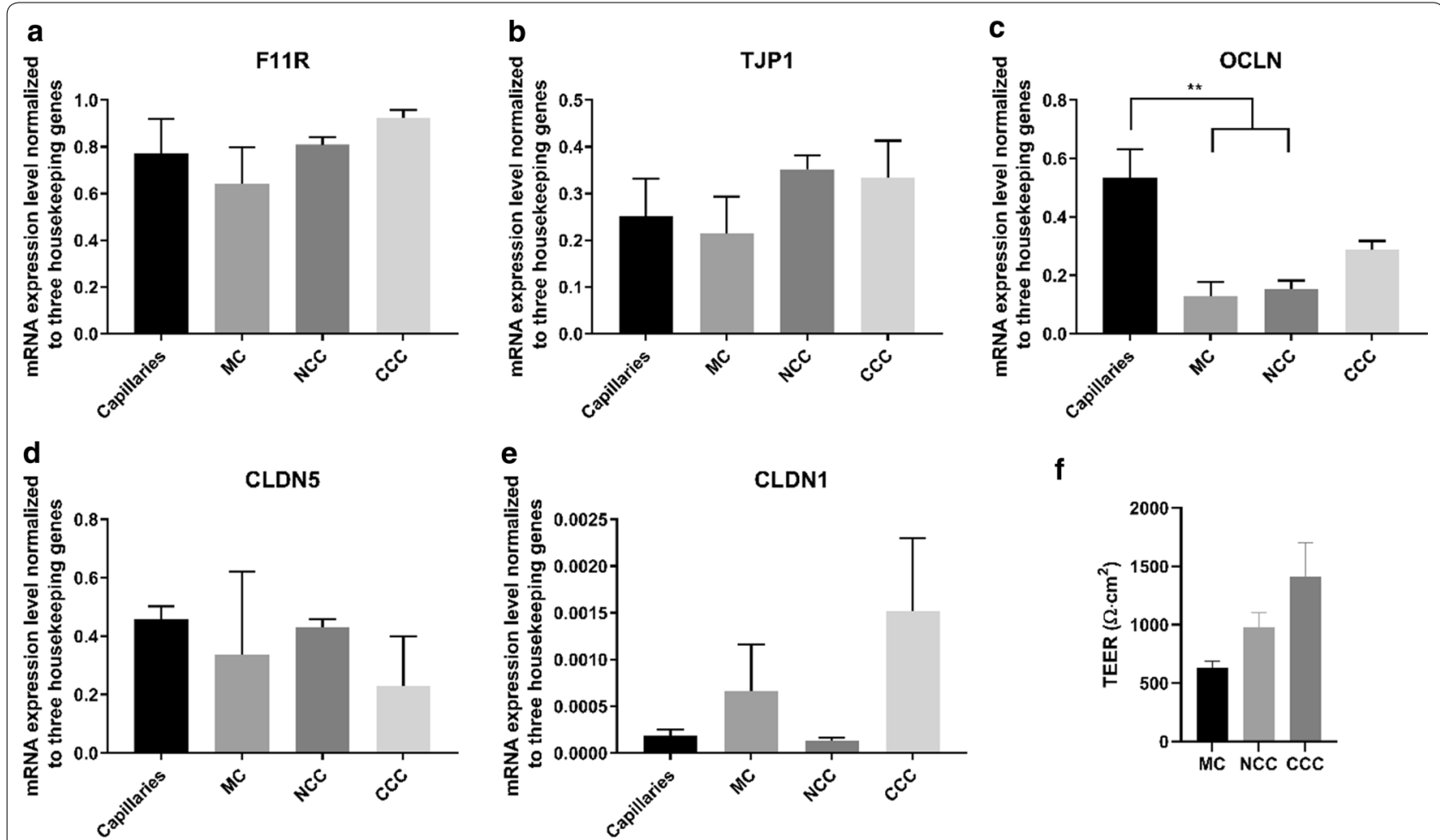

f

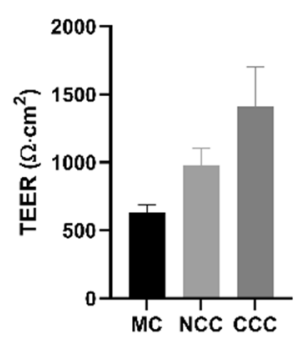

Fig. 2 Tight junction proteins. a Quantitative mRNA expression levels of F11R. There were no significant differences in expression levels. b Quantitative mRNA expression levels of TJP1. There were no specific differences in expression levels. c Quantitative mRNA expression levels of OCLN. OCLN was significantly downregulated in MC and NCC compared to capillaries. $\mathbf{d}$ Quantitative mRNA expression levels of CLDN5. There were no significant differences in expression levels. e Quantitative expression levels of CLDN1. CLDN1 expression levels were low in all culture configurations. $n=3, N=3$. F: Trans-endothelial electrical resistance (TEER) in the different models, $n=4-6, N=4-17$. Please note that the $y$-axis are different in all graphs. F11R: JAM-1, TJP1: Zo-1, OCLN: Occludin, CLDN5: Claudin-5, CLDN1: Claudin-1, MC: Mono culture, NCC: Non-contact co-culture, CCC: Contact CO-culture. ${ }^{*}: \mathrm{P} \leq 0.05,{ }^{* *}: \mathrm{P} \leq 0.005$. Error bars are mean $+\mathrm{SEM}$ 
culture configurations was measured to ensure barrier integrity (Fig. 2f). The cell monolayers exhibited high barrier tightness, with TEER at 632 (118) $\Omega \cdot \mathrm{cm}^{2}, 977$ (278) $\Omega \cdot \mathrm{cm}^{2}$ and 1410 (506) $\Omega \cdot \mathrm{cm}^{2}$ for MC, NCC and CCC, respectively (Fig. 2f).

\section{ABC-type efflux pumps $A B C B 1, A B C G 2, A B C C 1$ and $A B C C 4$ responded differentially to culture}

Efflux transporters at the BBB represent a major obstacle in drug discovery and development, as many novel small drug candidates developed for brain diseases cannot cross the BBB due to active efflux. We evaluated to what degree the transcript levels of P-glycoprotein $(A B C B 1)$, Breast-cancer resistance related protein BCRP (ABCG2), Multidrug-resistance related protein 1, MRP1 (ABCC1) and Multidrug-resistance related protein 4, MRP4, $(A B C C 4)$ were altered in the cell cultures. We found that the expression level of $A B C B 1$ was significantly downregulated in all in vitro culture configurations as compared to the expression levels found in brain capillaries. Co-culture with astrocytes showed a tendency to increase the expression level of $A B C B 1$ in bovine brain endothelial cells (Fig. 3a). ABCG2 exhibited a tendency to decrease in the culture models as compared to the expression level in brain capillaries (Fig. 3b). We observed a significant increase in the expression levels of $A B C C 1$ in cultures as compared to capillaries. CCCs furthermore displayed higher expression levels than MCs (Fig. 3c). The level of $A B C C 4$ showed a tendency to increase in culture (Fig. 4d). Comparisons of the absolute expression levels showed that $A B C B 1$ and $A B C G 2$ were higher in all culture configurations and in brain capillaries, as compared to $A B C C 1$ and $A B C C 4$.
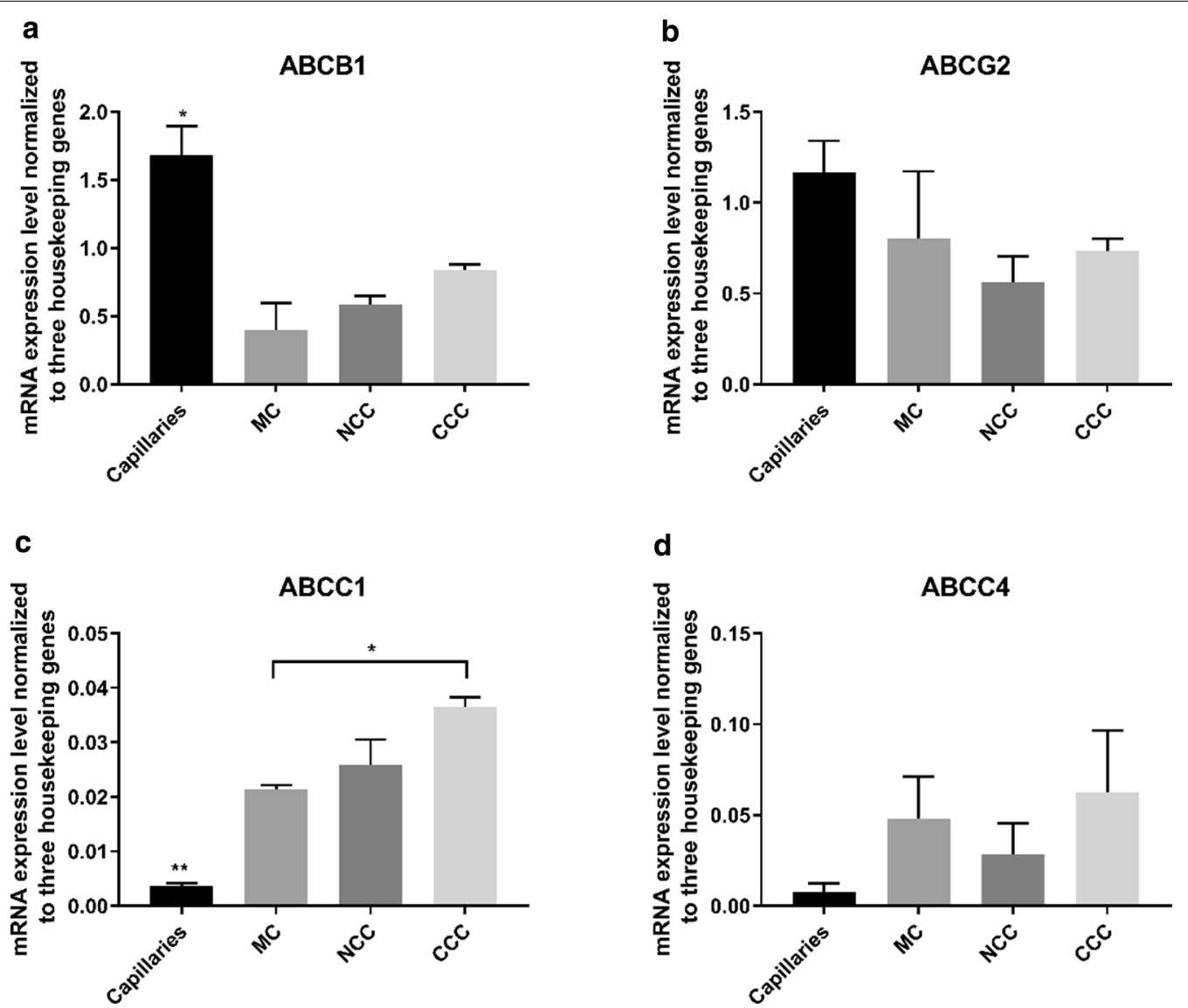

Fig. 3 Efflux transporters. a Quantitative mRNA expression levels of $A B C B 1$. The expression levels were significantly decreased from capillaries to all culture configurations. b Quantitative mRNA expression levels of $A B C G 2$. There were no significant differences in expression levels of $A B C G 2$. $\mathbf{c}$ Quantitative mRNA expression levels of $A B C C 1$. The expression of $A B C C 1$ was significantly increased from capillaries to all culture configurations. There was a significant increase in the expression in CCC compared to MC. $\mathbf{d}$ mRNA expression levels of $A B C C 4$. There were no significant differences in expression levels, although a non-specific increase was observed from capillaries to all culture configurations. ABCB1: Pgp, ABCG2: BCRP, ABCC1: MRP-1, ABCC4: MRP-4. MC: Mono culture, NCC: Non-contact co-culture, CCC: Contact co-culture. $n=3, N=3$. $: P \leq 0.5$. Error bars are mean $+S E M$ 

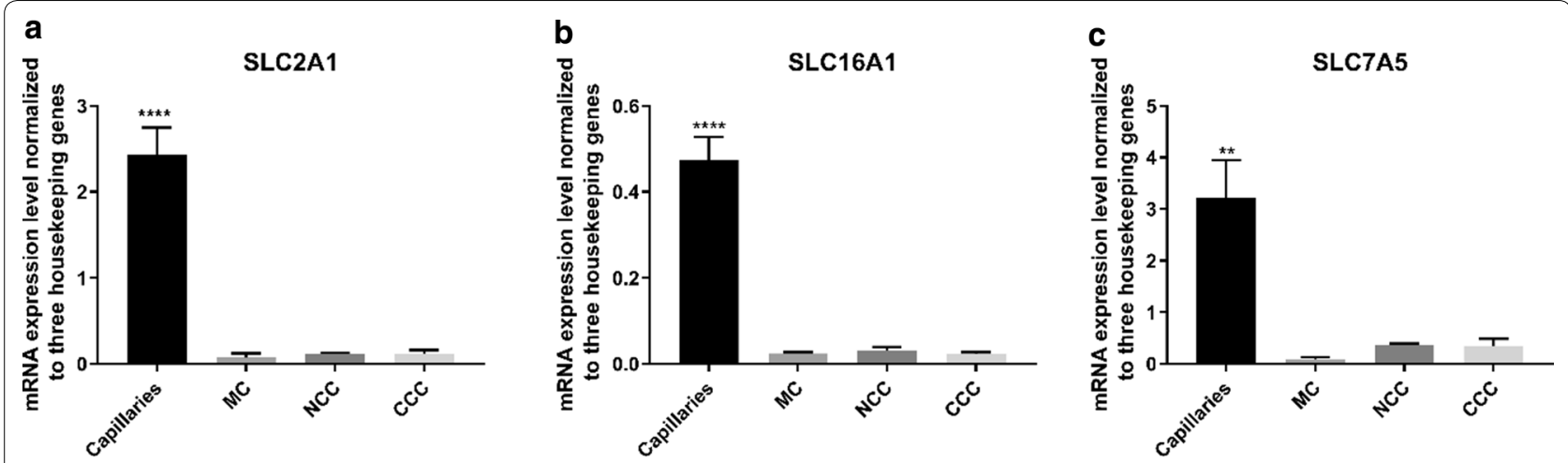

Fig. 4 SLC-transporters. a mRNA expression level of SLC2A1. SLC2A1 was significantly downregulated in all culture configurations compared to capillaries. b mRNA expression level of SLC16A1. A significant decrease was observed from capillaries to all culture configurations. $\mathbf{c}$ mRNA expression levels of SLC7A5. SLC7A5 was significantly downregulated from capillaries to all culture configurations. SLC2A1: GLUT1, SLC16A1: MCT-1, SLC7A5: LAT1. MC: Mono culture, NCC: Non-contact Co-culture, CCC: Contact Co-culture. $n=3, N=3 .{ }^{* *}: P \leq 0.05,{ }^{* * *}: P \leq 0.0005$. Error bars are mean + SEM

\section{SLC transporter transcript levels of LAT-1, GLUT-1} and MCT-1 were markedly lower in cultured endothelial cells, as compared to capillaries

Finally, we evaluated the expression levels of three key SLC transporters at the BBB, namely glucose transporter 1, GLUT-1, (SLC2A1), large neutral amino acid transporter 1, LAT-1, (SLC7A5) and monocarboxylate transporter 1, MCT1, (SLC16A1). A significant decrease in expression levels of SLC2A1, SLC16A1 and SLC7A5 was observed in the cell cultures compared to mRNA levels in brain capillaries (Fig. 4). The presence of astrocytes did not seem to affect the expression levels of $S L C 2 A 1$ or $S L C 16 A 1$. For $S L C 7 A 5$, we observed a non-significantly increase in the expression level in NCC and CCC compared to MC; although it was still significantly lower than the expression level in brain capillaries (Fig. 4c).

\section{Discussion}

In vitro models of the $\mathrm{BBB}$ must recapitulate many attributes of the native $\mathrm{BBB}$ by forming monolayers with restrictive barrier properties and expressing key proteins, such as TJs, SLC transporters and ABC transporters. Previous studies have shown that in vitro culture of brain capillary endothelial cells may alter the expression levels of important BBB markers and transporters as compared to the expression level in the native brain capillary endothelium $[5,9,18,19]$. This can have implications for the translational value of data obtained in in vitro experiments when correlating in vitro data to in vivo situations. We therefore aimed at examining the transcript levels of some key genes, known to be highly expressed in the native brain capillary endothelium, in in vitro cultures of brain capillary endothelial cells derived from bovine brains. The endothelial cells were cultured in MC, NCC and $\mathrm{CCC}$ configurations with rat astrocytes to examine whether astrocytes could rescue the phenotypic BBB features in the endothelial cells. Rat astrocytes in in vitro cultures of bovine endothelial cells are widely use due to the ability of rat astrocytes to proliferate for an extended culture period (see review: [15], and has been shown to induce several phenotypic BBB traits in bovine capillary endothelial cells $[2,11]$.

In the present study, we observed that expression of several important $\mathrm{BBB}$ genes was altered in the in vitro cultures of primary bovine brain endothelial cells as compared to brain capillaries. VWF, a widely used brain endothelial marker, was found to be higher expressed in the in vitro cultures than brain capillaries. A previous study has shown that $V W F$ exhibits a protective role in pathological conditions, such as seizures, hypoxia and spontaneous intracerebral hemorrhage by promoting and modulating $\mathrm{BBB}$ flexibility and opening during disease states [32]. This protective role of VWF indicates that the increased mRNA expression level of $V W F$ observed in the in vitro models is presumably due to an in vitro artifact, resulting from adaptation of the endothelial cells to the ambient conditions during in vitro culture. In addition, the expression level of $V W F$ was slightly increased in co-culture with rat astrocytes as compared to $\mathrm{MC}$. Several studies have shown that astrocytes in both CCC and NCC have proven efficient in inducing general BBB phenotypic traits in brain capillary endothelial cells [16]. This was also reflected in TEER measurements, where endothelial cells cultured in vitro showed the ability to form a barrier with high functional tightness, and co-culture with astrocytes led to an improved barrier tightness compared to MC. The transcript levels of genes involved in $\mathrm{TJ}$ formation were unaltered in the in vitro cultures as 
compared to those estimated in brain capillaries, except for $O C L N$. The brain capillary endothelial cells were thus still able to form tight monolayers, even though OCLN was found to be downregulated in the in vitro cultures. Saitou et al. [29] have previously shown that OCLN is not required for the formation intact TJs in epithelial cells derived from embryonic stem cells lacking OCLN. Similarly, they later found that mice lacking OCLN could still form intact TJs [30]. However, the mice underwent complex abnormalities, such as calcification around brain vessels, indicating another physiological role of OCLN in addition to $\mathrm{TJ}$ formation. In a recent study, Berndt et al. [3] showed a loss of TJ complexity in in vitro models compared to in vivo capillaries from human and mouse. They found that other not commonly investigated CLDN genes were abundantly present in vivo (CLDN11, -12 , -25 and -27 ) but almost depleted in vitro. The authors hypothesized that in vitro cultures tend to overexpress CLDN5. We did, however, observe unaltered expression levels of CLDN5 and CLDN1 in the in vitro cultures and in bovine brain capillaries, recapitulating the in vivo situations. We observed a low baseline expression of CLDN1 in cultured endothelial cells and capillaries as compared to the expression level of CLDN5, OCLN, TJP1 and F11R. This was in agreement with previous transcriptomic studies on human and murine brain capillary endothelial cells $[13,34,37,38]$, which similarly demonstrated that CLDN1 was low expressed, while OCLN, CLDN5, TJP1 and $F 11 R$ were highly abundant in murine and human brain capillary endothelial cells (Fig. 5a). This suggests no or negligible involvement of CLDN1 in tightening of the $\mathrm{BBB}$. This correlates with previous studies that report an intracellular localization of CLDN1 rather than localization at the junctional zones $[3,27]$. The expression level of $A B C B 1$ was found to be significantly downregulated, while $A B C C 1$ and $A B C C 4$ expression levels were increased in the cell culture models. Earlier mRNA transcript studies on bovine endothelial cells have also demonstrated a lower expression of a number of $\mathrm{ABC}$ transporters ( $A B C G 1, A B C A 1, A B C 2, A B C A 3, A B C A 7$ ) in cultures, as compared to capillaries [12].

Helms et al. [17] have previously found that P-gp, BCRP and at least one isoform of MRPs are expressed and functionally active in the bovine capillary endothelial cells co-cultured with rat astrocytes. Previous studies have shown that functional MRP1 is lacking at the BBB in mice $[7,36]$. Another study shows that the protein expression level of $\mathrm{ABCC} 1$ is under the limit of detection at the porcine BBB [39]. Comparing the data obtained in this study with previous transcriptomic studies on human and murine brain capillary endothelial cells, both $A B C B 1$ and $A B C G 2$ are the most dominant members of $\mathrm{ABC}$-transporter coding genes with expression levels being markedly greater than $A B C C 1$ and $A B C C 4$ across the species (Fig. 5b).

Taken together, the increases in mRNA levels of $A B C C 1$ and $A B C C 4$ are likely due to an in vitro artifact. A similar observation has been reported by Berezowski et al. [2] who showed that MRP1 transcript was present in culture but not in intact bovine capillaries. Another reason for the increase of $A B C C 1$, that we observe, may be the use of dexamethasone in culture medium that previously has been reported to induce the expression of functional $\mathrm{ABC}$-transporters in endothelial cells $[2$, 12]. These findings highlight the difficulty in finding suitable growth factors for enhancing the BBB phenotype in vitro, as the benefits in some cases can lead to in vitro culture artifacts in others, as observed with $A B C C 1$. This was also observed in the expression levels of $A L P$ between the different culture configurations.
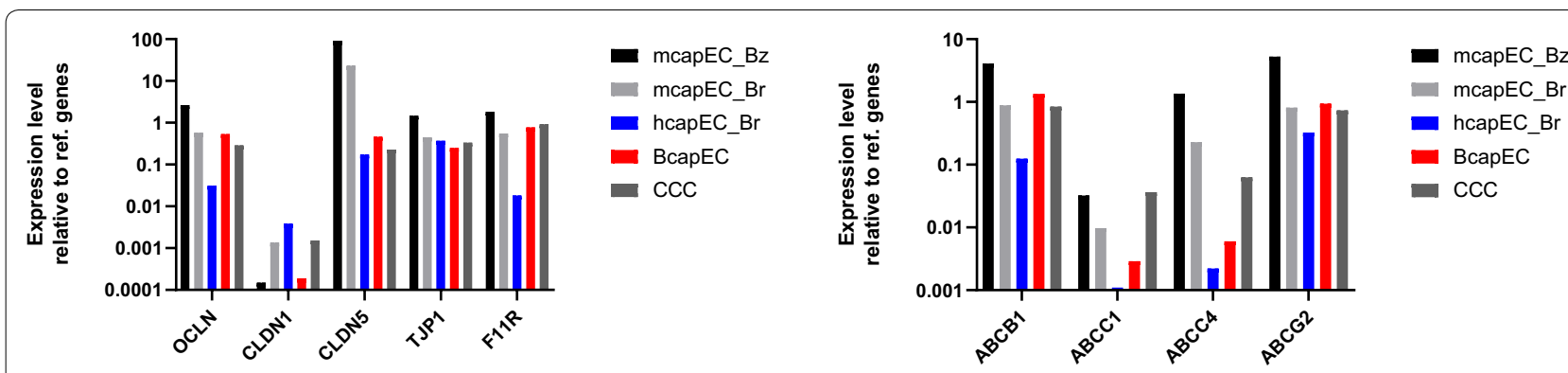

Fig. 5 Comparison of TJ and $A B C$ gene expression levels across different species. a mRNA expression levels of OCLN, CLDN1, CLDN5, TJP1 and F11R, and $\mathbf{b}$ mRNA expression levels of $A B C B 1, A B C C 1, A B C C 4$ and $A B C G 2$ in murine, human and bovine brain capillary endothelial cells and in endothelial cells cultured in contact co-culture (CCC) configuration with astrocytes. Transcriptomic data for murine brain capillary endothelial cells (mcapEC) is derived from transcriptomic databases from the Betsholtz lab (Bz) (http://betsholtzlab.org/VascularSingleCells/database.html) and the Barres lab (http://www.brainrnaseq.org/). Data for human brain capillary endothelial cells (hcapEC) are from the Barres lab et al. (Br). All data were normalized against endothelial HPRT-1, GAPDH and $\beta$-actin expression in the relative databases. Data are shown as mean values. Human data from Barres database: $n=2$. Murine data from Barres database: $n=2$. Murine data from Betsholtz database: $n=2$. Bovine data: $n=3, N=3$ 
A previous study proposed that direct contact between endothelial cells and astrocytes are necessary to maintain a high expression of $A L P$ in in vitro cultures [26]. However, we observed that cultured endothelial cells could maintain a high baseline expression level of $A L P$, independent of the culture configurations. The contrasting results suggest that the effects of astrocytes on $A L P$ may be lacking due to the presence of cAMP in differentiation media during culture, which similarly to astrocytes has been shown to induce $A L P$ in primary porcine brain endothelial cultures [4]. Thus, cAMP may cause the high baseline expression of $A L P$ in the cell culture models. In addition to $A B C B 1$, the transcript levels of SLC2A1, SLC16A1 and SLC7A5 were markedly downregulated by in vitro culture. The downregulation of SLC transporters is a general issue in primary cultures of brain endothelial cells [15]. Calabria et al. [5] have previously shown that in vitro culture of primary rat endothelial cells resulted in a downregulation of SLC transporters such as Slc2a1 and Slco1c1 and we have previously shown a similar downregulation of the mRNA expression levels of the insulin receptor and transferrin receptor from capillaries to bovine in vitro models $[18,19]$. This possible de-differentiation may pose a challenge for investigations on drug delivery routes involving transporters or receptors that are downregulated in in vitro models. Overall, we thus observed that for the SLCs there was a significant downregulation in cultures as compared to capillaries, which could not be rescued by astrocyte co-culture. It has, however, been shown that bovine pericytes may cause BBB induction as well [33], and we can therefore not exclude that presence of more cell types could increase SLC expression.

It should be noted that the capillary fraction here still contains astrocyte remnants, as previously shown [19]. This may lead to an overestimation of the level of SLCtransporters, which are also present in astrocytes. The findings in the present study emphasize the relevance of investigating expression levels of essential transporters in the BBB. Even though the expression levels were low in our model, it would be very interesting to investigate whether the transporters are active, yielding a potential novel model for investigations of SLC transporters as a drug delivery system. The differences between the mRNA expression in capillaries and our models may largely be a consequence of the environment in vitro that tries to mimic the BBB in vivo. The crude imitation of the microenvironment in vivo, the lack of contact to other cell types, such as pericytes, microglia and neurons, as well as lack of shear stress from blood flow, contributes largely to the differences in in vitro culture (as reviewed by [25]). In fact, the exposure of cells to laminar shear stress is often missing in many in vitro $B B B$ models. Incorporation of shear stress into the culture protocol of in vitro $\mathrm{BBB}$ models has previously been shown to promote $\mathrm{BBB}$ tightness and to upregulate the transcript levels of efflux transporters and several SLC transporters as compared to the static models $[8,10]$. Thus, introducing laminar shear stress to the culture protocol could be another approach for enhancing the phenotypic BBB traits in the in vitro BBB models.

The brain and the NVU are both complex systems to study and are therefore impossible to replicate in vitro, which makes it important to remember possible biases when using in vitro models. Furthermore, it is a field that largely uses primary cells, which are extremely sensitive to changes and the artificial conditions the in vitro models undergo during culture, as shown in the present study. Still, in vitro models are a vital tool in the investigation of potential drug delivery routes across the BBB. Co-culture with primary rat astrocytes had an inducing effect on the mRNA expression levels of some genes, although the overall impact on the model was minor. It is important to remember though, that to validate our results, protein localization and expression studies would benefit this study and highlight the importance of co-culture further. This study showed gene expression alterations of several important transporters in in vitro models of the BBB using primary bovine endothelial cells. It is therefore necessary to thoroughly characterize in vitro models before studying potential drug transport routes across the $\mathrm{BBB}$, as to be aware of the possibility of lower expression of $\mathrm{BBB}$ transporters due to culture.

\section{Conclusion}

We investigated differences in mRNA expression levels of selected marker proteins in brain capillaries and brain endothelial in vitro cultures. The present study confirms that the bovine endothelial cell/rat astrocyte co-culture models undergo a phenotypic alteration as compared to endothelial cells in intact brain capillaries. Mono-, noncontact- and contact co-cultures overall retained mRNA expression of junction-associated proteins. OCLN, however, was decreased on mRNA expression levels in vitro. The mRNA expression of the SLC transporters SLC2A1, SLC16A1 and SLC7A5 were markedly downregulated, and co-culture with astrocytes did not "rescue" the expression levels. Efflux transporters $A B C B 1$ and $A B C G 2$ were downregulated while $A B C C 1$ and $A B C C 4$ were upregulated compared to in vivo. 
At present, no in vitro model of the $\mathrm{BBB}$ mimics the native brain capillary endothelium fully. The bovine coculture in vitro models retain barrier properties and efflux transporter activity but have a suboptimal expression of important SLC transporters which must be considered when investigating trans-endothelial nutrient transport and SLC mediated drug delivery.

\section{Supplementary information}

Supplementary information accompanies this paper at https://doi. org/10.1186/s12987-020-00193-5.

Additional file 1: Figure S1. Quantitative analysis of the mRNA expression levels of the house keeping genes HPRT1, ACTB and GAPDH. Data are shown as mean of cycle quantification value. MC: mono culture, NCC: non-contact co-culture and CCC: contact co-culture. $n=5-6, N=3$. $P \leq 0.05,{ }^{* *}: P \leq 0.005$. Error bars are Mean + SEM. Figure S2. Quantitative analysis of the mRNA expression levels of the house keeping genes HPRT1, ACTB and GAPDH. Each of the dots represents the mean of the technical replicates $(N=3)$ for $5-6$ individual batches $(n=5-6)$, as mean of cycle quantification value. MC: mono culture, NCC: non-contact co-culture and CCC: contact co-culture. $n=5-3, N=3$. *: $P \leq 0.05,{ }^{* *}$ : $P \leq 0.005$. Error bars are Mean + SEM.

\section{Acknowledgements}

The authors wish to acknowledge the Lundbeck Foundation for support via the project grant "Research Initiative on Brain Barriers and Drug Delivery (RIBBDD)".

\section{Authors' contributions}

CG performed the experimental part of the work and drafted the first version of the manuscript, CG, BO and BB contributed to manuscript layout and writing, data treatment and figure design. All authors read and approved the final manuscript.

\section{Funding}

The study was funded via the project Grant "Research Initiative on Brain Barriers and Drug Delivery (RIBBDD)" (grant no. R155-2013-14113). The Lundbeck Foundation did not have a role in the design of the study and collection, analysis, and interpretation of data and in writing the manuscript.

\section{Availability of data and materials}

All data used for the publication are available from the corresponding author on request.

\section{Ethics approval and consent to participate \\ Not applicable.}

\section{Consent for publication}

Not applicable.

\section{Competing interests}

The authors declare that they have no competing interests.

Received: 2 February 2020 Accepted: 13 April 2020

Published online: 22 April 2020

\section{References}

1. Abbott NJ. Blood-brain barrier structure and function and the challenges for CNS drug delivery. J Inherit Metab Dis. 2013;36:437-49.

2. Berezowski V, Landry C, Dehouck MP, Cecchelli R, Fenart L. Contribution of glial cells and pericytes to the mRNA profiles of P-glycoprotein and multidrug resistance-associated proteins in an in vitro model of the blood-brain barrier. Brain Res. 2004:1018:1-9.
3. Berndt P, Winkler L, Cording J, Breitkreuz-Korff O, Rex A, Dithmer S, Rausch V, Blasig R, Richter M, Sporbert A, Wolburg H, Blasig IE, Haseloff RF. Tight junction proteins at the blood-brain barrier: far more than claudin-5. Cell Mol Life Sci. 2019;76:1987-2002.

4. Beuckmann C, Hellwig S, Galla HJ. Induction of the blood/brain-barrierassociated enzyme alkaline phosphatase in endothelial cells from cerebral capillaries is mediated via CAMP. Eur J Biochem. 1995;229:641-4.

5. Calabria AR, Shusta EV. A genomic comparison of in vivo and in vitro brain microvascular endothelial cells. J Cereb Blood Flow Metab. 2008:28:135-48.

6. Canfield SG, Stebbins MJ, Morales BS, Asai SW, Vatine GD, Svendsen CN, Palecek SP, Shusta EV. An isogenic blood-brain barrier model comprising brain endothelial cells, astrocytes, and neurons derived from human induced pluripotent stem cells. J Neurochem. 2017;140:874-88.

7. Cisternino S, Rousselle C, Lorico A, Rappa G, Scherrmann JM. Apparent lack of Mrp1-mediated efflux at the luminal side of mouse blood-brain barrier endothelial cells. Pharm Res. 2003;20:904-9.

8. Cucullo L, Hossain M, Puvenna V, Marchi N, Janigro D. The role of shear stress in Blood-Brain Barrier endothelial physiology. BMC Neurosci. 2011:12:40

9. Eigenmann DE, Durig C, Jahne EA, Smiesko M, Culot M, Gosselet F, Cecchelli R, Helms HCC, Brodin B, Wimmer L, Mihovilovic MD, Hamburger M, Oufir M. In vitro blood-brain barrier permeability predictions for GABAA receptor modulating piperine analogs. Eur J Pharm Biopharm. 2016:103:118-26.

10. Elbakary B, Badhan RKS. A dynamic perfusion based blood-brain barrier model for cytotoxicity testing and drug permeation. Sci Rep. 2020;10:3788.

11. Gaillard PJ, Voorwinden LH, Nielsen JL, Ivanov A, Atsumi R, Engman H, Ringbom C, de Boer AG, Breimer DD. Establishment and functional characterization of an in vitro model of the blood-brain barrier, comprising a co-culture of brain capillary endothelial cells and astrocytes. Eur J Pharm Sci. 2001;12:215-22.

12. Gosselet F, Candela P, Sevin E, Berezowski V, Cecchelli R, Fenart L. Transcriptional profiles of receptors and transporters involved in brain cholesterol homeostasis at the blood-brain barrier: use of an in vitro model. Brain Res. 2009;1249:34-42.

13. He L, Vanlandewijck M, Mae MA, Andrae J, Ando K, Del Gaudio F, Nahar K, Lebouvier T, Lavina B, Gouveia L, Sun Y, Raschperger E, Segerstolpe A, Liu J, Gustafsson S, Rasanen M, Zarb Y, Mochizuki N, Keller A, Lendahl U, Betsholtz C. Single-cell RNA sequencing of mouse brain and lung vascular and vessel-associated cell types. Sci Data. 2018:5:180160.

14. Hellemans J, Mortier G, De Paepe A, Speleman F, Vandesompele J. qBase relative quantification framework and software for management and automated analysis of real-time quantitative PCR data. Genome Biol. 2007;8:R19.

15. Helms HC, Abbott NJ, Burek M, Cecchelli R, Couraud PO, Deli MA, Forster C, Galla HJ, Romero IA, Shusta EV, Stebbins MJ, Vandenhaute E, Weksler B, Brodin B. In vitro models of the blood-brain barrier: an overview of commonly used brain endothelial cell culture models and guidelines for their use J Cereb Blood Flow Metab. 2016:36:862-90.

16. Helms HC, Brodin B. Generation of primary cultures of bovine brain endothelial cells and setup of cocultures with rat astrocytes. Methods Mol Biol. 2014;1135:365-82.

17. Helms HC, Hersom M, Kuhlmann LB, Badolo L, Nielsen CU, Brodin B. An electrically tight in vitro blood-brain barrier model displays net brain-toblood efflux of substrates for the ABC transporters, P-gp, Bcrp and Mrp-1. AAPS J. 2014;16:1046-55.

18. Hersom M, Helms HC, Pretzer N, Goldeman C, Jensen Al, Severin G, Nielsen MS, Holm R, Brodin B. Transferrin receptor expression and role in transendothelial transport of transferrin in cultured brain endothelial monolayers. Mol Cell Neurosci. 2016:76:59-67.

19. Hersom M, Helms HC, Schmalz C, Pedersen TA, Buckley ST, Brodin B. The insulin receptor is expressed and functional in cultured blood-brain barrier endothelial cells but does not mediate insulin entry from blood to brain. Am J Physiol Endocrinol Metab. 2018:315:E531-42.

20. Hertz $L$, Juurlink $B H$, Hertz E, Fosmark H. Preparation of primary cultures of mouse (rat) astrocytes. In: Shahar A, Vellis JVAD, Haber B, editors. A dissection and tissue culture manual of the nervous system. New York: Alan R. Liss, Inc; 1989. p. 105-8. 
21. Kurosawa T, Tega Y, Higuchi K, Yamaguchi T, Nakakura T, Mochizuki T, Kusuhara H, Kawabata K, Deguchi Y. Expression and functional characterization of drug transporters in brain microvascular endothelial cells derived from human induced pluripotent stem cells. Mol Pharm. 2018;15:5546-55.

22. Lelu S, Afadzi M, Berg S, Aslund AK, Torp SH, Sattler W, Davies LC. Primary porcine brain endothelial cells as in vitro model to study effects of ultrasound and microbubbles on blood-brain barrier function. IEEE Trans Ultrason Ferroelectr Freq Control. 2017;64:281-90.

23. Lippmann ES, Azarin SM, Kay JE, Nessler RA, Wilson HK, Al-Ahmad A, Palecek SP, Shusta EV. Derivation of blood-brain barrier endothelial cells from human pluripotent stem cells. Nat Biotechnol. 2012;30:783-91.

24. Livak KJ, Schmittgen TD. Analysis of relative gene expression data using real-time quantitative PCR and the 2(-Delta Delta C(T)) Method. Methods. 2001;25:402-8.

25. Matarese G, La Cava A, Horvath TL. In vivo veritas, in vitro artificia. Trends Mol Med. 2012;18:439-42.

26. Meyer J, Rauh J, Galla HJ. The susceptibility of cerebral endothelial cells to astroglial induction of blood-brain barrier enzymes depends on their proliferative state. J Neurochem. 1991;57:1971-7.

27. Morcos Y, Hosie MJ, Bauer HC, Chan-Ling T. Immunolocalization of occludin and claudin-1 to tight junctions in intact CNS vessels of mammalian retina. J Neurocytol. 2001;30:107-23.

28. Pfaffl MW. A new mathematical model for relative quantification in realtime RT-PCR. Nucleic Acids Res. 2001;29:e45.

29. Saitou M, Fujimoto K, Doi Y, Itoh M, Fujimoto T, Furuse M, Takano H, Noda T, Tsukita S. Occludin-deficient embryonic stem cells can differentiate into polarized epithelial cells bearing tight junctions. J Cell Biol. 1998;141:397-408.

30. Saitou M, Furuse M, Sasaki H, Schulzke JD, Fromm M, Takano H, Noda T, Tsukita S. Complex phenotype of mice lacking occludin, a component of tight junction strands. Mol Biol Cell. 2000;11:4131-42.

31. Soltany-Rezaee-Rad M, Sepehrizadeh Z, Mottaghi-Dastjerdi N, Yazdi MT, Seyatesh N. Comparison of SYBR Green and TaqMan real-time PCR methods for quantitative detection of residual $\mathrm{CHO}$ host-cell DNA in biopharmaceuticals. Biologicals. 2015;43:130-5.

32. Suidan GL, Brill A, De Meyer SF, Voorhees JR, Cifuni SM, Cabral JE, Wagner DD. Endothelial Von Willebrand factor promotes blood-brain barrier flexibility and provides protection from hypoxia and seizures in mice. Arterioscler Thromb Vasc Biol. 2013;33:2112-20.
33. Vandenhaute E, Dehouck L, Boucau MC, Sevin E, Uzbekov R, Tardivel M, Gosselet F, Fenart L, Cecchelli R, Dehouck MP. Modelling the neurovascular unit and the blood-brain barrier with the unique function of pericytes. Curr Neurovasc Res. 2011;8:258-69.

34. Vanlandewijck M, He L, Mae MA, Andrae J, Ando K, Del Gaudio F, Nahar K, Lebouvier T, Lavina B, Gouveia L, Sun Y, Raschperger E, Rasanen M, Zarb Y, Mochizuki N, Keller A, Lendahl U, Betsholtz C. A molecular atlas of cell types and zonation in the brain vasculature. Nature. 2018;554:475-80.

35. Veszelka S, Toth A, Walter FR, Toth AE, Grof I, Meszaros M, Bocsik A, Hellinger E, Vastag M, Rakhely G, Deli MA. Comparison of a rat primary cell-based blood-brain barrier model with epithelial and brain endothelial cell lines: gene expression and drug transport. Front Mol Neurosci. 2018;11:166.

36. Wijnholds J, deLange EC, Scheffer GL, van den Berg DJ, Mol CA, van der Valk M, Schinkel AH, Scheper RJ, Breimer DD, Borst P. Multidrug resistance protein 1 protects the choroid plexus epithelium and contributes to the blood-cerebrospinal fluid barrier. J Clin Invest. 2000;105:279-85.

37. Zhang Y, Chen K, Sloan SA, Bennett ML, Scholze AR, O'Keeffe S, Phatnani HP, Guarnieri P, Caneda C, Ruderisch N, Deng S, Liddelow SA, Zhang C, Daneman R, Maniatis T, Barres BA, Wu JQ. An RNA-sequencing transcriptome and splicing database of glia, neurons, and vascular cells of the cerebral cortex. J Neurosci. 2014;34:11929-47.

38. Zhang Y, Sloan SA, Clarke LE, Caneda C, Plaza CA, Blumenthal PD, Vogel H, Steinberg GK, Edwards MS, Li G, Duncan JA 3rd, Cheshier SH, Shuer LM, Chang EF, Grant GA, Gephart MG, Barres BA. Purification and characterization of progenitor and mature human astrocytes reveals transcriptional and functional differences with mouse. Neuron. 2016;89:37-53.

39. Zhang Z, Uchida Y, Hirano S, Ando D, Kubo Y, Auriola S, Akanuma SI, Hosoya KI, Urtti A, Terasaki T, Tachikawa M. Inner blood-retinal barrier dominantly expresses breast cancer resistance protein: comparative quantitative targeted absolute proteomics study of CNS barriers in pig. Mol Pharm. 2017;14:3729-38.

\section{Publisher's Note}

Springer Nature remains neutral with regard to jurisdictional claims in published maps and institutional affiliations.
Ready to submit your research? Choose BMC and benefit from:

- fast, convenient online submission

- thorough peer review by experienced researchers in your field

- rapid publication on acceptance

- support for research data, including large and complex data types

- gold Open Access which fosters wider collaboration and increased citations

- maximum visibility for your research: over $100 \mathrm{M}$ website views per year

At BMC, research is always in progress.

Learn more biomedcentral.com/submissions 